\title{
ILIZAROV AND LOCKING PLATE FIXATION FOR CLOSED BICONDYLAR TIBIAL PLATEAU FRACTURES- A PROSPECTIVE STUDY
}

\author{
R. Kartheek ${ }^{1}$, Kotilingam Kodandapani ${ }^{2}$
}

${ }^{1}$ Consultant, Department of Orthopaedics, Osmania Medical College/Osmania General Hospital.

2 Professor and HOD, Department of Orthopaedics, Osmania Medical College/Osmania General Hospital.

\begin{abstract}
BACKGROUND

In bicondylar tibial plateau fractures, the most frequently used treatment is ORIF with screws and plates; however, the soft tissue complications are frequently reported. Minimally-invasive Ilizarov technique is an alternative. The purpose of this study was to compare and analyse the clinical and radiological results of locking plate and Ilizarov technique in bicondylar tibial plateau fractures treated at a level I trauma centre.
\end{abstract}

\section{MATERIALS AND METHODS}

The patients with closed isolated bicondylar tibial fractures (Schatzker V/VI) were included in the study. Fifteen patients (8 of type $\mathrm{V}$ and 7 of type VI) in one group were treated using locked plating system and fifteen patients (5 of type V and 10 of type VI) in another group were treated with Ilizarov technique. Pre- and post-operatively, conventional radiographs, CT scans, hospital stay and complications were evaluated. The outcomes were evaluated using modified Rasmussen clinical and radiological criteria.

\section{RESULTS}

The two groups were similar demographically. Both the techniques achieved acceptable osseous reduction. When compared with internal fixation, Ilizarov had increased average range of motion $\left(124^{\circ}\right.$ vs $\left.117^{\circ}\right)$, decreased complications $(p=0.01)$, reduced hospital stay (0.001), earlier weight-bearing and marginally faster recovery (outcome in terms of modified Rasmussen clinical assessment score) at 6 months. But the outcomes were not significantly different at 1 year. In this study, Ilizarov technique had slight favourable outcome compared to locked plating group.

\section{CONCLUSION}

The Ilizarov method produces a good clinical outcome and is a valuable alternative treatment for bicondylar tibial plateau fractures with added advantage of decreased hospital stay, decreased waiting time for definitive surgery and early weight bearing.

\section{KEYWORDS}

Ilizarov, LCP, LISS, Proximal Tibia, Tibial Plateau, External Fixation, ORIF, Schatzker Type V and VI.

HOW TO CITE THIS ARTICLE: Kartheek R, Kodandapani K. Ilizarov and locking plate fixation for closed bicondylar tibial plateau fractures- a prospective study. J. Evolution Med. Dent. Sci. 2017;6(64):4670-4675, DOI: 10.14260/Jemds/2017/1010

\section{BACKGROUND}

Tibial plateau fractures are uncommon injuries, representing only $1.2 \%$ of all fractures. ${ }^{[1]}$ Fractures of the proximal tibia, especially comminuted intra-articular type as a result of high energy trauma produces a challenging clinical scenario. Age, skin conditions, osteoporosis further increase the obstacles in the healing process.

Historically, closed treatment of tibial plateau fractures including traction and immobilisation resulted in unacceptably high rates of complications like malunion and joint stiffness. ${ }^{[2]}$ The goal of the treatment of tibial plateau fractures is to achieve a stable, well-aligned, mobile, pain-free joint and to minimise the risk of post-traumatic osteoarthritis. Complex tibial plateau fractures are always accompanied by serious soft tissue damage, which influences the strategy of treatment. Difficulties arise in finding a balance between adequate surgical exposure and protection

Financial or Other, Competing Interest: None.

Submission 12-06-2017, Peer Review 30-07-2017,

Acceptance 04-08-2017, Published 10-08-2017.

Corresponding Author:

Dr. R. Kartheek

5/254, Gugudu Road,

Narpala, Anantapur-515425,

Andhra Pradesh.

E-mail: drkartheekortho@gmail.com

DOI: $10.14260 /$ jemds $/ 2017 / 1010$ of the already compromised soft tissue environment. With advancements in internal fixation principles, various operative modalities of treatments are now available but no ideal treatment has yet evolved.

In highly unstable bicondylar fractures, sufficient fixation with adequate reduction of the fragments can be accomplished by direct reduction and bilateral plating. [3] The main problem with this strategy lies in the additional soft tissue damage caused by medial and lateral surgical incisions with an increased rate of skin necrosis and superficial or deep infections. The locking plates allow internal fixation on lateral side of proximal tibia through minimal incisions, thereby achieving anatomic reduction and stable internal fixation with minimal soft tissue problems. ${ }^{[4]}$

Because of these soft tissue complications, minimally invasive external fixation techniques have been reported with some success.[5,6] Ilizarov technique is the most successful external fixation technique. In the classic Ilizarov technique according to the original recommendations, the reduction and fixation of the fracture fragments can be made with almost no soft-tissue exposure and blood loss. Other advantages are no need of second surgery for hardware removal after the fracture has healed. The fracture alignment can be made by distraction or compression of the fixator even after the surgery. It is stable enough to allow early weightbearing and no need to use a staged protocol. Problems with 
Ilizarov modality includes pin tract infection and loosening, inadequate reduction and unstable fixation.

To our knowledge, only one randomised controlled trial comparing Ilizarov and non-locking buttress plate fixation for bicondylar tibial plateau fractures is available.[7] All other studies available are retrospective and compared nonspecifically with different modalities of internal and external fixation. ${ }^{[8-15]}$ Both open and closed fractures are included in the studies, which leads to bias in assessing internal fixation with Ilizarov. No prospective studies comparing Ilizarov and open reduction and internal fixation with locking plate for closed bicondylar tibial plateau fractures were available. The purpose of this study, which was an observational comparative study was to compare the outcome of open reduction and internal locking plate fixation and that of Ilizarov fixation for patients with closed bicondylar tibial plateau fractures.

\section{MATERIALS AND METHODS}

From October 2012 to September 2015, we conducted a nonrandomised controlled trial comparing open reduction and locking plate fixation and Ilizarov fixation with percutaneous and/or limited open reduction techniques for patients with closed bicondylar tibial plateau fractures (Schatzker) [16] types V and VI and Orthopaedic Trauma Association (OTA) ${ }^{[17]}$ types C1, C2, and C3 at a level I trauma centre. After obtaining Institutional Ethical Committee approval, the present study was undertaken and informed consent was obtained from all individual participants included in the study. Based on our hospital previous year operation theatre records, the total number of type 5 and type 6 tibial plateau fractures operated was 72 cases, so we thought that 15 cases of type V or VI tibial plateau fractures treated by Ilizarov is an achievable target in one year period and a reasonable number to perform the study. The one year was kept as a time limit; however, we could reach our target of 15 cases in 11 months. The controls were selected as the first 15 cases from whom consent was obtained for their inclusion in study and have not opted for Ilizarov but wanted to undergo the conventional ORIF with plating.

\section{Inclusion Criteria}

All patients had a closed bicondylar tibial plateau fracture of Schatzker type V or VI or OTA types C1 or C2 or C3). Only the patients who are admitted within two days after sustaining fracture and had given informed consent are included in the study.

\section{Exclusion Criteria}

Patients were excluded if they had any of the following features: open tibial plateau fracture (Gustilo grade I/II/III),[18] compartment syndrome, open growth plates, an age of more than sixty-five years, a pathologic fracture, polytrauma, bilateral fractures, ipsilateral femoral fractures, a pre-existing joint disease (Osteoarthritis, inflammatory arthritis or a prior fracture), a severe systemic illness (uncontrolled diabetes or hypertension, active cancer, renal failure or a medical contraindication for surgery) or any neurological condition that would interfere with rehabilitation.

From October 2012, the patients who fulfilled the criteria are given the choice of internal or external fixation and the first 15 fractures consecutively treated with internal fixation and first fifteen fractures consecutively treated with Ilizarov were included in the study. They were followed up for one year post-operatively. The mean follow-up period was 56.4 weeks. Of the 30 fractures in the study, 15 were treated with locking plate fixation and 15 with Ilizarov fixation.

In the emergency, first the patient's haemodynamic condition was stabilised and the associated injuries were ruled out. Once the patient was medically stable, the limb was temporarily splinted and radiographic analysis was completed. This workup included standard antero-posterior (AP) and lateral knee and tibia radiographs as well as computed tomography scan with $3 \mathrm{D}$ reconstruction were used to better evaluate the fracture pattern and articular involvement.

For all the patients, lower tibial pin traction was applied on Bohler Braun splint. In the internal fixation group, the definitive surgery was performed after the soft tissue condition improved as evidenced by resolution of the oedema and fracture blisters and appearance of skin wrinkles.

Both treatments were performed with the patient under spinal anaesthesia with prophylactic antibiotic coverage administered and image-intensifier assistance. All procedures were performed by the single surgeon with any one of the residents' assistance. Open reduction and internal fixation is done in supine position. Ilizarov fixation is done on traction table. No arthroscopy was used to assess the reduction. In the internal fixation group, 5 were treated using standard locking plates and 10 were treated using Less Invasive Stabilisation System (LISS). In the Ilizarov group, 6 fractures were treated with percutaneous reduction and 9 were treated with limited open reduction of the articular surface and bone grafting. Bone graft was used in 10 cases of plating group. Bone graft when used was harvested from single iliac crest. No bone graft substitutes were used.

In the open reduction and internal fixation group, standard AO principles of exposure and fixation were used. When the standard locking plate was used, medial or anterior midline exposure was made. The articular surface was reduced, provisionally fixed with K-wires and $4.5 \mathrm{~mm}$ cancellous screws were used for compression, then locking plate was applied on the medial surface of tibia. When LISS was used, the plate was inserted in submuscular fashion on the lateral side (Figure 2B) after the fracture was reduced and fixed with $\mathrm{K}$-wires and 4.5 cancellous screws. Bone grafting was done in required cases after elevating the articular surface. Standard wound closure over drains was performed.

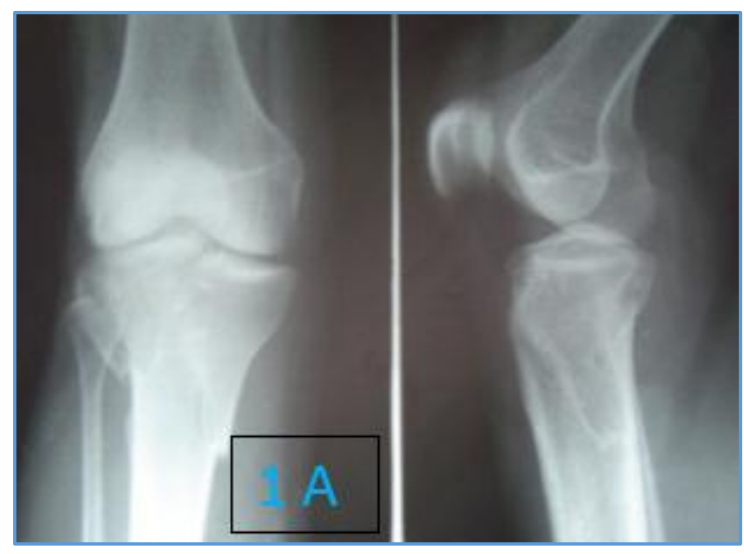



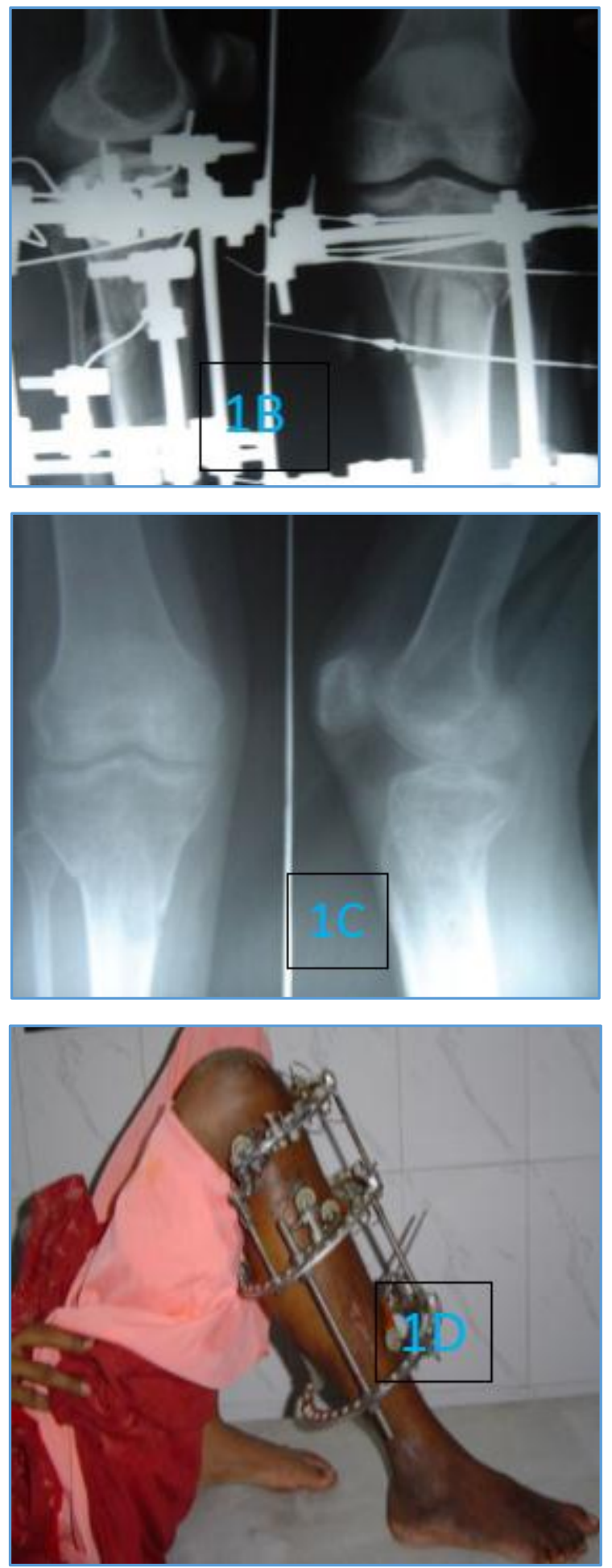

Figure. 1A-1D. 36-year-old Female with Bicondylar Tibial Plateau Fracture managed with Ilizarov

Fixator. 1A-Pre-operative AP and Lateral $X$-rays, $1 B$ Post-operative AP and Lateral $X$-rays, $1 C$-Follow-up $A P$ and Lateral $X$-rays and $1 D$-Clinical Photo demonstrating Knee Flexion at 4 Weeks PostOperative Follow-up Period

In Ilizarov group, the proximal ring was placed at the level of the fibular head after elevating the articular surface (Figure 1B). The reduction was achieved with the help of traction table or reduction forceps or percutaneously inserted elevators. Depending on the complexity of the fracture, three ring or four ring Ilizarov construct was used (Figure 1D). No plates were used. Drains were used when bone grafting was done.

Physiotherapy was started immediately after the operation to maintain knee and ankle motion in both groups. In the open reduction and internal fixation group, weightbearing was restricted for 6 weeks and then partial weightbearing was allowed progressing to full weight-bearing by 3 months. Weight-bearing as tolerated was allowed in the Ilizarov group immediately postoperatively. All patients were followed for a minimum of 1 year with radiographs at 3 weeks, 6 weeks, 9 weeks, 3 months, 6 months and 12 months postoperatively.

Post-operative and most recent radiographs for each patient were evaluated by both the authors according to Rasmussen's radiological scoring. This scoring system evaluates joint depression, condylar widening and varus or valgus angulation. Postoperative reductions with less than 5 mm of residual joint depression on antero-posterior or lateral views were considered good. Postoperative reductions with more than $10 \mathrm{~mm}$ of residual joint depression on anteroposterior or lateral views were rated as poor. All radiographs included in this study were taken in the Radiology Department of our Institute.

The primary outcome measure was the modified Rasmussen's scoring system for clinical assessment at 6 months and 1 year postoperatively. Secondary outcome measures included manual testing of stability in varus and valgus, complications, reoperation, the quality of radiographic reduction and the presence of degenerative osteoarthritis.

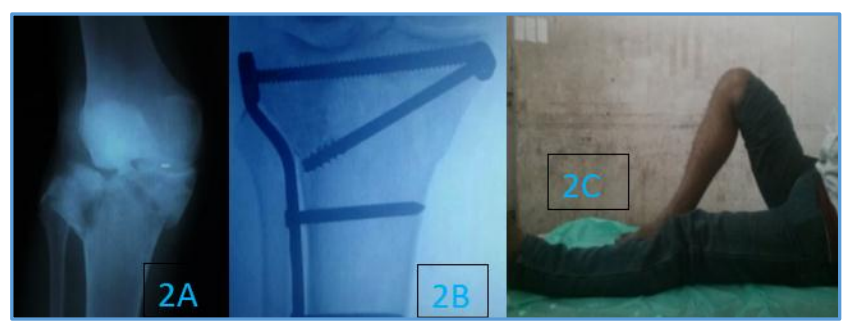

Figure 2A-2C. 24-year-old Male Patient with Bicondylar Tibial Plateau Fracture managed with Locking Plate Fixation. Pre-operative AP (2A), Postoperative AP at 3 Months Follow-up (2B) and Clinical Photo demonstrating Knee Flexion at 6 Months Follow-up (2C)

\section{Statistical Analysis}

The statistical software namely SPSS 15.0, MedCalc 9.0.1 and Systat 12.0 were used for the analysis of the data. Descriptive and inferential statistical analysis has been carried out in the present study. Results on continuous measurements are presented on Mean + SD (Min-Max) and results on categorical measurements are presented in Number (\%). Analysis of parametric data was carried out with a Student t-test. Nonparametric data was analysed using the Chi-square test or Fisher's exact test. Values of 'p' less than 0.05 ( $p<0.05)$ were considered statistically significant.

\section{RESULTS}

There were no significant differences in age, gender or fracture distribution between patients who had Ilizarov 
fixation or locked plating fixation (Table 1). There was no significant difference $(p=0.4257)$ between the groups with respect to the mechanism of injury, which included a road traffic accident (ten patients in Ilizarov group and 8 patients in open reduction and locked plating group), fall (two patients in the Ilizarov group and five patients in the locked plating group) and work related injury (three patients in the Ilizarov group and two patients in the locked plating group).

\begin{tabular}{|c|c|c|c|}
\hline Variable & $\begin{array}{c}\text { Open } \\
\text { Reduction } \\
\text { and Internal } \\
\text { Fixation (n=15) }\end{array}$ & $\begin{array}{c}\text { Ilizarov } \\
\text { (n=15) }\end{array}$ & P value \\
\hline Age (years) & $44.73 \pm 10.64$ & $43.20 \pm 10.98$ & 0.7007 \\
\hline $\begin{array}{c}\text { Gender } \\
\text { Male }\end{array}$ & 12 & 13 & 0.6242 \\
Female & 3 & 2 & 0.7125 \\
\hline $\begin{array}{c}\text { Laterality } \\
\text { Right } \\
\text { Left }\end{array}$ & 6 & 7 & 0.46 \\
\hline $\begin{array}{c}\text { Fracture Type } \\
\text { Schatzker type V } \\
\text { Schatzker type VI }\end{array}$ & 8 & 8 & 5 \\
\hline \multicolumn{2}{|c|}{ Table 1. Patient Demographics and Distribution of } \\
Fracture Types \\
\hline
\end{tabular}

*The values are given as the mean and the standard deviation.

The patients who were treated with Ilizarov fixator had a better range of motion averaging $124.6^{\circ}$ than locked plating group's average range of motion $117.3^{\circ}$, but the difference was not significant $(p=0.0902)$ (Table 2). Postoperatively, there was no significant difference $(p=0.5438)$ between the groups with respect to the quality of the reduction. Anatomical outcomes were evaluated using the Rasmussen's radiological scoring.[19] Good to excellent results were achieved in 14 patients in Ilizarov group and in 11 patients in locked plating group. Fair results were achieved in one patient in Ilizarov group and in three patients in locked plating group. One patient had poor outcome in locked plating group. The group treated with Ilizarov demonstrated statistically significant $(\mathrm{p}=0.0485)$ higher mean modified Rasmussen's scoring system for clinical assessment compared with locked plating group at six months after the injury. At 1 year after injury the mean score for Ilizarov group was still high, but not statistically significant (Table 2).

\begin{tabular}{|c|c|c|c|}
\hline Parameter & $\begin{array}{c}\text { Open Reduction and } \\
\text { Internal Fixation } \\
\text { (n=15) }\end{array}$ & $\begin{array}{c}\text { Ilizarov } \\
\text { (n=15) }\end{array}$ & P value \\
\hline $\begin{array}{c}\text { Range of } \\
\text { motion (deg)* }\end{array}$ & $117.3^{\circ} \pm 12.3$ & $124.6 \pm 10.4$ & 0.0902 \\
\hline $\begin{array}{c}\text { Rasmussen's radiological scoring* } \\
13.33 \pm 4.76\end{array}$ & $14.27 \pm 3.45$ & 0.5438 \\
\hline \multicolumn{3}{|c|}{ Modified Rasmussen's scoring system for clinical } \\
assessment* \\
\hline $\begin{array}{c}6 \text { months } \\
1 \text { year }\end{array} \quad \begin{array}{c}24.67 \pm 5.09 \\
26.80 \pm 3.05\end{array}$ & $27.87 \pm 3.18$ & 0.0485 \\
& $19.40 \pm 2.32$ & 0.1174 \\
\hline $\begin{array}{c}\text { Hospital stay } \\
\text { (days)* }\end{array}$ & $19.3 \pm 7.02$ & $11.2 \pm 4.75$ & 0.001 \\
\hline $\begin{array}{c}\text { Time to definitive surgery (in days) * } \\
12.73+5.92\end{array}$ & $7.67+4.37$ & 0.0126 \\
\hline $\begin{array}{c}\text { Table 2. Comparison of different Outcome Parameters and } \\
\text { Hospital Stay which Influence the Cost of Surgery }\end{array}$ \\
\hline
\end{tabular}

*The values are given as the mean and the standard deviation.

Three patients had infections in Ilizarov group (two were superficial pin tract infections and one deep infection) and 3 patients had infections after open reduction locking plate fixation. One pin tract infection was controlled by oral antibiotic therapy and another required soft tissue debridement. The one with deep infection involving proximal tibia in Ilizarov group was treated with debridement and antibiotic therapy. Of the three infections in locked plating group, two were superficial soft tissue infections controlled by soft tissue debridement and antibiotic therapy and another was a deep infection and treated with repeated debridement and plate removal. Overall, there were 21 complications in 7 patients in locked plating group, whereas 9 complications occurred in 4 patients in Ilizarov group $(\mathrm{p}=0.4497)$ (Table 3).

\begin{tabular}{|c|c|c|}
\hline Complication & $\begin{array}{c}\text { Open Reduction and } \\
\text { Internal Fixation } \\
(n=15)\end{array}$ & $\begin{array}{c}\text { Ilizarov } \\
(n=15)\end{array}$ \\
\hline $\begin{array}{l}\text { Delayed wound healing } \\
\text { (minor) }\end{array}$ & 3 & 0 \\
\hline $\begin{array}{l}\text { Pin tract infection } \\
\text { (minor) }\end{array}$ & 0 & 2 \\
\hline Deep infection & 1 & 1 \\
\hline Varus collapse & 3 & 0 \\
\hline Knee instability & 2 & 0 \\
\hline $\begin{array}{c}\text { Hardware impingement } \\
\text { (minor) }\end{array}$ & 3 & 1 \\
\hline Stiffness & 4 & 1 \\
\hline Equinus deformity & 0 & 1 \\
\hline Arthritis & 5 & 3 \\
\hline
\end{tabular}

*The values are given in number of patients.

Mean number of days between the fracture and the time of surgery was less for Ilizarov group compared to the locked plating group, as the open reduction and internal fixation had to be delayed till the soft tissues recover $(p=0.0126)$ (Table 2). The average time to definitive surgery was higher in locking plate fixation group $(12.73+5.92)$ compared to Ilizarov fixation group $(7.67+4.37)$ with a 'p' value of 0.0126 . The mean total length of stay in the hospital was also significantly shorter for the group that had the Ilizarov fixation (11.2 \pm 4.75 days) compared with that for the group managed with open reduction and locking plate fixation (19.3 \pm 7.02 days $)(p=0.001)$. This was primarily due to the increased hospital stay for patients managed with open reduction and internal fixation, whose surgery is delayed for the soft tissues to recover and had complications developed and required multiple procedures.

\section{DISCUSSION}

Bicondylar tibial plateau fractures are notoriously dangerous fractures, which require operative treatment and often associated with high complication rates and poor clinical outcome. Generally classified as Schatzker type V/VI or A0/OTA 41C are treated with various internal and external fixation techniques. ORIF with dual plating[20] is reported recently in achieving anatomical reduction and stable 
fixation, but associated with high complication rate.[7] This has led to the usage of different modalities of treatment like Ilizarov and locking plate for fixation.

The results of circular fixator frame described by Watson, Young et al and Stamer et al revealed reasonable outcomes with dramatically reduced infection rates compared to that by internal fixation.[21,6,22] In their randomised controlled study of ORIF and circular fixator for tibial plateau fractures, Canadian Orthopaedic Trauma Society (COTS) ${ }^{[7]}$ reported higher complications, delayed return of function and longer hospital stay in open reduction and internal fixation group and similar fracture quality reduction in both groups. But in COTS study, no locking plates were used.

Biomechanical studies demonstrated unilateral locking plate fixation as effective as double plating in preventing medial condyle displacement in a bicondylar tibial plateau fracture model.[4,23] In their study, Ryan J Krupp et al reported decreased time of union and lesser complications with locking plate fixation compared to external fixation for bicondylar tibial plateau fracture fixation.[12] In their study, CC Chan et al[8] reported no significant difference in the anatomical outcome between the patients treated by internal or external fixation for bicondylar tibial plateau fractures. All these studies included both open and closed tibial fractures and distribution of open tibial fractures in their treatment groups was not reported, which could lead to bias if open fractures were not equally distributed in the treatment groups. And also, these studies have compared different modalities of external and internal fixation techniques leading to complexity in comparing outcomes of heterogeneous treatment groups.

To our knowledge, no study in the literature compared the outcomes of closed bicondylar tibial plateau fractures treated by locking plate fixation and Ilizarov technique. This was the purpose of our study.

The present study suggests that there is no significant difference in restoration of the osseous anatomy between the Ilizarov group and the locking plate fixation group. Our study also confirmed the increased rate of complications seen following open reduction and internal fixation of these fractures compared to Ilizarov technique, despite the use of locking plates and single incision exposure for fracture fixation.

The rate of deep infection in the open reduction and locking plate fixation group in the present study was $5 \%$. These findings are supported in studies by Krupp et al[12] with $7 \%$ infection rate and Cole et al ${ }^{[24]}$ with an infection rate of $4 \%$. The deep infection rate in Ilizarov group is also $5 \%$, but was controlled with debridement and antibiotic therapy, whereas in plating group it required implant removal. Varus collapse $(20 \%)$ and stiffness $(26.6 \%)$ are the next frequent complications in the locked plating group. Although, the increased knee range of motion in the Ilizarov group $\left(124^{\circ}\right)$ compared to locked plating group $\left(117^{\circ}\right)$ is not statistically significant $(p=0.09)$. This is a clinically important improvement in motion.

Ilizarov group had a slight faster recovery from the injury than the locking plate fixation group demonstrated by shorter hospital stay and improved modified Rasmussen's scoring system for clinical assessment at six months. This might be due to the decreased soft-tissue dissection, earlier weightbearing and the lower post-operative complication rate.
Other advantages of Ilizarov are it allows earlier definitive intervention with minimal soft tissue dissection in patients with compromised soft tissues; and allows early mobilisation which is one of the four basic principles formulated by AO (Arbeitsgemeinschaft für Osteosynthesefragen).[25]

This is a prospective study and has no sample loss in followup. It compares outcomes of two specific treatments (locking plate fixation and Ilizarov) for closed bicondylar tibial plateau fractures in demographically similar patient groups. The limitations are non-randomisation, short followup period and small sample size. Conditions like posttraumatic arthritis, which require long-term follow-up are not better evaluated given the shorter follow-up period. Long term studies with large sample size are required for better evaluation of degenerative arthritis following bicondylar tibial plateau fractures.

\section{CONCLUSION}

Both techniques provided acceptable fracture reduction and clinical outcome at one year followup. But the Ilizarov modality provided reduced time to definitive surgery, minimal soft tissue dissection, decreased hospital stay, earlier weight-bearing, marginally faster recovery and reduced overall complications. The earlier clinical outcomes (6 months) are marginally superior for Ilizarov, but the outcomes at one year are similar in both groups. So, the Ilizarov technique provides an alternative modality of treatment to open reduction and locking plate fixation for management of closed bicondylar tibial plateau fractures.

\section{REFERENCES}

[1] Cole PL SJ, Watson JT. Tibial plateau fractures. Skeletal trauma: basic science management and reconstruction. Saunders Elsevier, Philadelphia 2009.

[2] DeCoster TA, Nepola JV, el-Khoury GY. Cast brace treatment of proximal tibia fractures. A ten-year follow-up study. Clinical orthopaedics and related research 1988;231:196-204.

[3] Canale ST, Beaty JH. Campbell's operative orthopaedics. Elsevier 2013.

[4] Egol KA, Su E, Tejwani NC, et al. Treatment of complex tibial plateau fractures using the less invasive stabilization system plate: clinical experience and a laboratory comparison with double plating. The Journal of trauma 2004;57(2):340-6.

[5] Rockwood CA, Bucholz RW, Heckman JD, et al. Rockwood and greens: fractures in adults. Lippincott Williams \& Wilkins, Philadelphia 2010.

[6] Watson JT. High-energy fractures of the tibial plateau. The Orthopedic clinics of North America 1994;4:72352 .

[7] Society COT. Open reduction and internal fixation compared with circular fixator application for bicondylar tibial plateau fractures. Results of a multicenter, prospective, randomized clinical trial. The Journal of bone and joint surgery American 2006;88(12):2613-23.

[8] Chan CC, Keating J. Comparison of outcomes of operatively treated bicondylar tibial plateau fractures by external fixation and internal fixation. Malaysian Orthopaedic Journal 2012;6(1):7-12. 
[9] Ali AM, Hashmi M, Saleh M, et al. Outcome of complex fractures of the tibial plateau treated with a beamloading ring fixation system. J Bone Joint Surg $\mathrm{Br}$ 2003;85(5):691-9.

[10] Jansen H, Frey SP, Doht S, et al. Medium-term results after complex intra-articular fractures of the tibial plateau. Journal of Orthopaedic Science 2013;18(4):569-77.

[11] Mallik AR, Covall DJ, Whitelaw GP. Internal versus external fixation of bicondylar tibial plateau fractures. Orthopaedic review 1992;21(12):1433-6.

[12] Krupp RJ, Malkani AL, Roberts CS, et al. Treatment of bicondylar tibia plateau fractures using locked plating versus external fixation. Orthopedics 2009;32(8).

[13] Pun TB, Krishnamoorthy VP, Poonnoose PM, et al. Outcome of schatzker type $\mathrm{V}$ and VI tibial plateau fractures. Indian Journal of Orthopaedics 2014;48(1):35-41.

[14] Metcalfe D, Hickson CJ, McKee L, et al. External versus internal fixation for bicondylar tibial plateau fractures: systematic review and meta-analysis. Journal of orthopaedics and traumatology 2015;16(4):275-85.

[15] Mahadeva D, Costa ML, Gaffey A. Open reduction and internal fixation versus hybrid fixation for bicondylar/severe tibial plateau fractures: a systematic review of the literature. Archives of orthopaedic and trauma surgery 2008;128(10):116975.

[16] Schatzker J. Compression in the surgical treatment of fractures of the tibia. Clinical orthopaedics and related research 1974;105:220-39.

[17] Fracture and dislocation compendium. Orthopaedic trauma association committee for coding and classification. Journal of orthopaedic trauma 1996;10 Suppl 1:v-ix, 1-154.
[18] Gustilo RB, Anderson JT. Prevention of infection in the treatment of one thousand and twenty-five open fractures of long bones: retrospective and prospective analyses. The Journal of bone and joint surgery American 1976;58(4):453-8.

[19] Rasmussen PS. Tibial condylar fractures. Impairment of knee joint stability as an indication for surgical treatment. The Journal of bone and joint surgery American 1973;55(7):1331-50.

[20] Prasad GT, Kumar TS, Kumar RK, et al. Functional outcome of schatzker type V and VI tibial plateau fractures treated with dual plates. Indian Journal of Orthopaedics 2013;47(2):188-94.

[21] Stamer DT, Schenk R, Staggers B, et al. Bicondylar tibial plateau fractures treated with a hybrid ring external fixator: a preliminary study. Journal of orthopaedic trauma 1994;8(6):455-61.

[22] Young MJ, Barrack RL. Complications of internal fixation of tibial plateau fractures. Orthopaedic review 1994;23(2):149-54.

[23] Gosling T, Schandelmaier P, Marti A, et al. Less invasive stabilization of complex tibial plateau fractures: a biomechanical evaluation of a unilateral locked screw plate and double plating. Journal of orthopaedic trauma 2004;18(8):546-51.

[24] Cole PA, Zlowodzki M, Kregor PJ. Treatment of proximal tibia fractures using the less invasive stabilization system: surgical experience and early clinical results in 77 fractures. Journal of orthopaedic trauma 2004;18(8):528-35.

[25] Rüedi TP, Murphy WM. AO principles of fracture management. Thieme, Stuttgart 2007. 